American Journal of Nursing Science
2015; 4(3): $45-49$
Published online April 14, 2015 (http://www.sciencepublishinggroup.com/j/ajns)
doi: 10.11648/j.ajns.20150403.11
ISSN: 2328-5745 (Print); ISSN: $2328-5753$ (Online)

\title{
Determinants towards Implementation of Nursing Process
}

\author{
Zewdu Shewangizaw*, Abera Mersha \\ College of Medicine and Health Sciences, Arbaminch University, Arbaminch, Ethiopia
}

\section{Email address}

Mershaabera@gmail.com (Abera M.),WERET83Z@outlook.Com (Zewdu S.)

\section{To cite this article:}

Zewdu Shewangizaw, Abera Mersha. Determinants towards Implementation of Nursing Process. American Journal of Nursing Science. Vol. 4, No. 3, 2015, pp. 45-49. doi: 10.11648/j.ajns.20150403.11

\begin{abstract}
Nursing Process is a systematic method which utilizes scientific reasoning, problem solving and critical thinking to direct nurses in caring for patients effectively however, little is known about factors affecting the implementation of nursing process. The study intended to assess factors affecting implementation of nursing process among nurses in Arbaminch General Hospital, Ethiopia. Institutional based cross-sectional study with quantitative data collection through Self-administered pre-tested Semi Structured questionnaire and observational checklist used among randomly selected 105 nurses. Data analysis was done by SPSS version 15 for its objectives. Out of 105 studies 98 were participated in the study with $93.3 \%$ response rate. Forty two $(42.85 \%)$ of the total respondents were working in a stressful working environmental. Thirty five (35.7\%) of respondents were challenged to provide their nursing care due to patients inability to collect the required material for care provision. Factor affecting implementation of nursing process were working in a stressful environment were 0.23 times less likely to implement nursing process than those working in organized environment (OR: 0.23, [95\% CI: (0.07-0.78)], highly knowledgeable nurses were 8.78 times more likely to implementation of nursing process than nurses who were not knowledgeable $(\mathrm{OR}$ : 8.78 , [95\%CI: $(2.97-$ 77.48)] and economic status of patient to collect material for nursing care were negatively associated with implementation of nursing process(OR: 0.07, [95\%CI: (0.02-0.31)]. The study has identified lack of facility from organizational factors, economic status of the patient to collect material for nursing care, early discharge, lack of cooperation and complicated problems from patient related factors and level of knowledge were among those factors highly affecting nursing process implementation. Nearly, one third of respondents have consistent with the implementation of nursing process in the clinical setting. This factors cause poor quality of nursing care disorganized caring system, conflicting role, medication error and re-admission with similar problems, dissatisfaction with the care patients have received, and increased mortality. Recommendation: The essence of nursing process for client lies on the great benefits to the client, nurses and nursing profession as a whole. So, to provide quality of nursing care the management body of the hospital should flow and supervise the implementation of nursing process in the hospital, the health professional should train periodically and Information should be disseminated regarding nursing process.
\end{abstract}

Keywords: Nursing Process, Satisfaction, Knowledge

\section{Background}

Nursing Process is a systematic method which utilizes scientific reasoning, problem solving and critical thinking to direct nurses in caring for patients effectively (1). Nursing process as problem solving approach and evidence based method which involves different steps and it is a goal oriented method of caring for patients (2).

The nursing process is widely accepted method and has been suggested as a scientific method to guide procedures and quality nursing care. More recently, the process has been defined as a systematic and dynamic way to deliver nursing care, operating through five interrelated steps: assessment, diagnosis, planning, implementation and evaluation $(3,4)$.
Nursing process is a cycle that never ends, roadmap that ensures good nursing care and improves patient outcomes (5, 6). As patient needs change, the nursing process allows the nurse to change the patient's plan of care to ensure that care is tailored to the patient's present needs. Nursing process allows health care team to observe and interact with the patient, and not just become the task they are performing $(5,6)$.

According to current American and Canadian standards, nursing practice demands the efficient use of the nursing process and professional participation in activities that contributes to the permanent development of knowledge about this methodology(4). 
Different health care organization such as world health organization (WHO), International Council of Nursing and the American Joint Commission on Accreditation of Hospital Nursing Service Standards highly recommended that nursing process should be used in nursing documentation and promoted the use of the nursing process in nursing care (7).

The nursing process should be established in care practice at all health care institutions, with in hospitals as well as in the community as a whole $(4,8)$.

Nursing process is a cycle that never ends, roadmap that ensures good nursing care and improves patient outcomes (9, 10). As patient needs change, the nursing process allows the nurse to change the patient's plan of care to ensure that care is tailored to the patient's present needs. Nursing process allows health care team to observe and interact with the patient, and not just become the task they are performing $(9,10)$.

Research evidence showed positive relationship between practicing nursing process and decreased hospital stay, and increased satisfaction (11). An intervention study on the effect of training nurses on nursing process implementation showed that the practice resulted in decreased hospital stay from 6.44 to 5.37 , increased mean quality of discharge education practice from 2.24 to 12.2 , increased mean quality of documentation by staff from 2 to 23.4, increasing quality of care, increasing level of nurses' satisfaction, changing nurse's attitude regarding nursing care, decreasing energy consumed during care and increasing the ability of patients for self-care (12).

Results of previous studies indicated that patients who received care according to nursing process were more satisfied than patients who received usual nursing care, as a result of nurses spend more time with patient and patient had more participation in their care (11).

Nursing involves assisting others with basic human needs using a holistic approach, and the patient is defined as someone who needs care. The majority of nurses have knowledge of the nursing process, but they do not apply it in practice. Due to this, there are problems which are, decrease quality of care and ineffectiveness of the service (13).

Similarly, it is difficult to bring significant improvement in nursing care if nurses don't use nursing process to assess, plan, implement, and evaluate clinical conditions of the client Moreover, malpractice of nursing process will affect quality of nursing care as a result of different factors. (14).

According to study done at Addis Ababa indicate that, working overtime $(81.8 \%)$, working without payment (12\%), misconduct $(10.9 \%)$, high flow of patient, knowledge error, conflicting roles, high employee turnover and for $35.4 \%$ less recognition, unsympathetic manager, $16.1 \%$ in a disorganized organizational structure, early discharge and poor participation of patients associated with professional, organizational and patient related factors in implementation of nursing process (15).

Assessing the determinant factors which affect the implementation, nursing process have vital role in the proper implementation of the nursing process in Arbaminch Hospital.

\section{Methods}

Institutional based cross-sectional study with quantitative data collection through Self-administered pre-tested Semi Structured questionnaire and observational checklist used among randomly selected 105 nurses at Arbaminch General Hospital. Study make eligible all nurses available during the study period at Arbaminch Hospital.

Sample size were calculated by using single population proportion formula with level of significance of $95 \%$, marginal error $5 \%$, with $10 \%$ non-respondents rate. The study tool also pretested for consistency on $10 \%$ of study subjects at Chencha district hospital.

According to the study nursing process were operationalized as a process in which nurses are used to solve patient's problems by using the five steps i.e. Assessment, Nursing Diagnoses, Planning, Implementation and Evaluation and patient hospital stay: A patient who is staying in hospital for getting nursing care.

Data analysis were done by SPSS Version 15 software to identify factors in multivariate bivariate analysis. Other variables were measured by frequency and percentage. The confidentiality of the study participant were kept entire the study process and informed consent also gotten from the participant. Moreover, ethical clearance were gotten from Arbaminch Hospital.

\section{Result}

\subsection{Socio Demographic Characteristics}

Out of 105 study participant, 98 were participated in the study with $93.3 \%$ response rate. About the sex distribution 46 of them were males and 52 were females. Related to the religion $46(46.9 \%)$ of the respondents were orthodox and $1(1.02 \%)$ were catholic. The mean age of the study participant was 37.4 years old. Due to marital status $60(61.22 \%)$ of the respondents were married, 29(29.6\%) were single. (See table 1 below).

Table 1. Selected socio demographic characteristics of study participant in Arbaminch General Hospital, 2014

\begin{tabular}{llll}
\hline Characteristics & & Frequency & Percentage \\
\hline \multirow{2}{*}{ Sex } & Male & 46 & 46.9 \\
& Female & 52 & 53.1 \\
& Orthodox & 46 & 46.9 \\
Religion & Protestant & 44 & 44.8 \\
& Islam & 3 & 3.06 \\
& Catholic & 1 & 1.02 \\
& $<24$ & 6 & 6.12 \\
Age & $25-44$ & 70 & 71.4 \\
& $45-54$ & 13 & 13.26 \\
& $55-64$ & 9 & 9.18 \\
& $<5$ years & 26 & 26.53 \\
Work & 5-10years & 40 & 40.81 \\
experience & $10-15$ years & 6 & 6.12 \\
& $15-20$ years & 16 & 16.32 \\
& 20-25 years & 4 & 4.08 \\
\hline
\end{tabular}




\subsection{Professionals Related Factors Affecting Nursing Process}

Seventy six (77.55\%) of the respondents had no misbehavior record on their personal file while $11(11.22 \%)$ had misbehavior record and remaining $11(11.22 \%)$ did not know misconduct record on the personal file. Regarding orientation forty one $(41.83 \%)$ of the total respondents have got satisfying orientation while they join their organization whereas $50(51.02 \%)$ of respondents did not get satisfying orientation.

Regarding on method of making implementation of nursing $43(43.87 \%)$ make visible their nursing related activities. In this study, forty seven (47.97\%) of respondents were committed error on implementation of nursing process. Among those twelve $(25.5 \%), 13(27.7 \%), 22(46.8 \%)$ had committed slap, executive, and knowledge errors respectively.

\subsection{Organizational Related Factors Affecting Implementation of Nursing Process}

According to the current study, 42(42.85\%) of respondents were anxious in working time due to high patient flow, $9(9.18 \%)$ were from due misconception of physicians, $3(3.06 \%)$ were from harassing co-workers, $2(2.02 \%)$ were from demanding patients, and $11(11.22 \%)$ were from unsympathetic managers.

At the same time the study shows that, the misconception of less important of nursing process $9(9.18 \%)$ and new reporting system $9(9.18 \%)$ affect the implementation of nursing process. Among the respondent, 35 (35.7\%) of them believe that there working environment is stress full. (See table 2 below).

Table 2. Selected organizational factors affecting implementation of nursing process among nurse at Arbaminch General Hospital, 2014

\begin{tabular}{|c|c|c|c|}
\hline Character & & Frequency & Percent (\%) \\
\hline \multirow{2}{*}{$\begin{array}{l}\text { Availability of } \\
\text { equipment }\end{array}$} & Available & 38 & 38.8 \\
\hline & Not available & 60 & 61.2 \\
\hline \multirow{3}{*}{ Overtime work } & \multirow{3}{*}{$\begin{array}{ll}\text { Yes } & \text { with payment } \\
& \text { without payment }\end{array}$} & 50 & 51.02 \\
\hline & & 7 & 7.14 \\
\hline & & 41 & 41.8 \\
\hline \multirow{2}{*}{$\begin{array}{l}\text { Satisfied with } \\
\text { payment }\end{array}$} & Yes & 1 & 2.0 \\
\hline & No & 49 & 98.0 \\
\hline \multirow{2}{*}{$\begin{array}{l}\text { Oriented while } \\
\text { joining the current } \\
\text { organization }\end{array}$} & Yes & 41 & 41.8 \\
\hline & No & 57 & 58.2 \\
\hline
\end{tabular}

\subsection{Patient related Factors Affecting the Implementation of Nursing Process}

Poor understanding of the principle of nursing process, poor patient economic status to implement designed nursing care plan, it need hospital stay and need of follow up and are patent related factors in implementation of nursing process (See figure1 ).

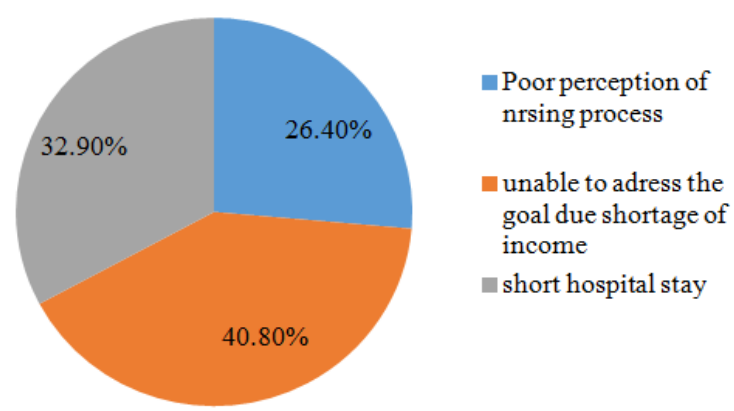

Figure 1. Selected patient related factors in implementation of nursing process in Arbaminch general hospital, 2014

\section{Nursing Process Implementation and Its Correlates}

Characteristics such as, work place, nurses who were working in a stressful environment were 0.23 times less likely to implement nursing process than those working in an organized environment (OR: 0.23, [95\% CI: (0.07-0.78)]. Neglecting working environment had no association with implementation of nursing process. Working in a hospital with high facility were 5.50 times more likely to implement nursing process than those working in lack of facility (OR: 5.50, [95\%CI: (2.18-13.74)].

Highly knowledgeable nurses were 8.78 times more likely to implementation of nursing process than nurses who were no knowledgeable (OR: 8.78, [95\%CI: (2.97-77.48)]. Moderately knowledgeable nurses were positively associated with implementation of nursing process (OR: 3.49, [ 95\%CI: (1.03-11.82)].

From patient related factors economic status of patient to collect material for nursing care were negatively associated with implementation of nursing process (OR:0.07, [95\%CI:(0.02-0.31)] and (OR: 0.04, [95\%CI, (0.01-0.21)], (OR: 0.19, [ 95\%CI, ( 0.05-0.73)] were early discharge and due to lack of cooperation.(See table 3 below).

Table 3. Relationship of implementation of nursing process by selected variables in Arbaminch General Hospital,2014

\begin{tabular}{|c|c|c|c|c|}
\hline \multirow{2}{*}{\multicolumn{2}{|c|}{ Characteristics }} & \multicolumn{2}{|c|}{$\begin{array}{l}\text { Nursing process } \\
\text { Implemented }\end{array}$} & \multirow[t]{2}{*}{$\operatorname{AOR}(95 \% C I)$} \\
\hline & & Yes & No & \\
\hline \multirow{2}{*}{ Sex } & Male & $14(14.3)$ & $32(32.7)$ & $0.83(0.36-1.92)$ \\
\hline & Female & $18(18.4)$ & $34(34.7)$ & 1.0 \\
\hline \multirow{3}{*}{ Work place } & Stressful & $7(7.1)$ & $28(28.6)$ & $0.23(0.07-0.78)^{*}$ \\
\hline & Negligent & $15(15.3)$ & $29(29.6)$ & $0.47(0.16-1.36)$ \\
\hline & Organized & $10(10.2)$ & $9(9.2)$ & 1.0 \\
\hline \multirow{2}{*}{ Facility } & Available & $21(21.4)$ & $17(17.3)$ & $5.50(2.18-13.74) *$ \\
\hline & Lack of facility & 11(11.2) & $49(50)$ & 1.0 \\
\hline \multirow{3}{*}{ Knowledge } & $\begin{array}{l}\text { Highly } \\
\text { knowledgeable }\end{array}$ & $13(13.3)$ & $10(10.2)$ & $8.78(2.97-77.48) *$ \\
\hline & $\begin{array}{l}\text { Moderately } \\
\text { knowledgeable }\end{array}$ & $15(15.3)$ & $29(29.6)$ & $3.49(1.03-11.82)^{*}$ \\
\hline & $\begin{array}{l}\text { Not } \\
\text { knowledgeable }\end{array}$ & $4(4.1)$ & $27(27.5)$ & 1.0 \\
\hline \multirow{4}{*}{$\begin{array}{l}\text { Patient } \\
\text { related } \\
\text { factors }\end{array}$} & Economic status & $5(5.1)$ & $22(22.4)$ & $0.07(0.02-0.31)^{*}$ \\
\hline & Early discharge & $3(3.1)$ & $23(23.4)$ & $0.04(0.01-0.21)^{*}$ \\
\hline & Not cooperative & $11(11.2)$ & $17(17.3)$ & $0.19(0.05-0.73)^{*}$ \\
\hline & Cooperative & $13(13.3)$ & $4(4.1)$ & 1.0 \\
\hline
\end{tabular}




\section{Discussion}

This study was tried to assess factors affecting implementation of nursing process among nurses in Arbaminch General Hospital. Among nurses in Arbaminch General Hospital .32(32.7\%) were implemented nursing process while $66(67.3 \%)$ of them were not implemented nursing process.

From the total respondents $50(51.02 \%)$ of them said the dissatisfying aspect of their job was caring for so many patients followed by rules being made up without staff or respondents in mind $28(28.57 \%)$ and useless paper work $9(9.18 \%)$ and new reporting system $9(9.18 \%)$. In research conducted about nurse to physician communication, nursing workload definitely affects the time that a nurse can allow to various tasks. Under a heavy workload, nurses may not have sufficient time to perform tasks that can have a direct effect on patient safety. It shows that when nurses become dissatisfied about their job the nursing care to be provided will not have systemic approach. In other words nursing process may not be implemented in hospital with high patient flow beyond the capacity of nurses.

In this study $37(37.75 \%)$ of nurses have cared for more than 16 patients per day, 28(28.57\%) were cared for $10-15$ patients while $36(36.73 \%)$ were cared for 5-10 patients and $1(1.02 \%)$ were cared for less than five patients. This shows that there significant difference between researches conducted in USA and this study due to the average nurse to patient ratio in high income countries is almost eight times greater than in low income countries.

Sixty six $(36.7 \%)$ believe that the cause was less or no appreciation for work done. But research conducted in selected hospitals in Addis Ababa most study participants responded that the main cause for employment turnover were less recognition for work and less growth opportunity for growth(15).

In this study forty two (42.85\%) of respondents were anxious in working time from high patient flow, 25(25.51\%) were because of every one does not do their job, $9(9.18 \%)$ were from abusive family, $9(9.18 \%)$ were from rude physicians, $3(3.06 \%)$ were from harassing co-workers, $2(2.02 \%)$ were from demanding patients, and 11(11.22\%) were from unsympathetic managers. Research finding in Addis Ababa indicated that $28.1 \%$ of respondents have had anxiety from large nurse to patient ratio, rude physician challenges and unsympathetic manager (15).

Thirty five $(35.7 \%)$ of respondents were challenged to provide their nursing care due to patients inability to collect the required material for care provision. This shows that there significant difference between the studies made in Addis Ababa $40.6 \%$ of respondents reported that they were not able to complete the nursing care they planned because of early discharge of patients (15).

Twenty three $(23.34 \%)$ of respondents were highly knowledgeable and 44(44.9\%) were moderately knowledgeable while 31(31.63\%) had not knowledgeable.

In this study the characteristics of work place, nurses who were working in a stressful environment were 0.23 times less likely to implement nursing process than those working in a organized environment (OR: 0.23, [95\% CI: (0.07-0.78)]. Neglecting working environment had no association with implementation of nursing process. Working in a hospital with high facility were 5.50 times more likely to implement nursing process than those working in lack of facility (OR: 5.50, [95\%CI: (2.18-13.74)].

Highly knowledgeable nurses were 8.78 times more likely to implementation of nursing process than nurses who were no knowledgeable (OR: 8.78, [95\%CI,(2.97-77.48)]. Moderately knowledgeable nurses were positively associated with implementation of nursing process (OR: 3.49, [95\%CI: (1.03-11.82)]. It shows knowledge is the most important to implement nursing process.

In this study economic status patient to collect the material for nursing care were negatively associated with implementation of nursing process (OR: 0.07, [95\% CI, $(0.02-$ $0.31)$ and (OR: 0.04, [95\%CI, ( 0.01-0.21)], (OR: 0.19, [95\%CI,( 0.05-0.73)] were early discharge and due to lack of cooperation.

\section{Conclusion}

The study identified that lack of facility from organizational factors, economic status of the patient, early discharge, level of knowledge and lack of were among those factors affecting nursing process implementation.

Lack of equipment supply in hospitals for giving nursing care was highly affecting implementation of nursing process.

\section{References}

[1] Altamier p. (2010). Evaluation of implementation of nursing process, among nurses working in Abakaliki metropolis, Abakaliki: West Africa.

[2] Emen, A.N. (2007).Issues on the foundation of nursing process.

[3] Fernandez-sola $\mathrm{C}$, et al. Strategies to develop the nursing process and nursing care plans in the health system in Bolivia. International Nursing Review (2011), 58, 392-399.

[4] Pokorski S, et al. Nursing process: from literature to practice. What are we actually doing? Rev Latino-am Enfermagem, maio-junho, (2009), 17(3):302-7.

[5] Global health council, Building a Winning Nursing Work Force for HIV-Care in Ethiopia. Accessed on October 14/2010, www.change.org

[6] Freitas, M. C., Queiroz, T. A., \& Sousa, J. A. V.: The nursing process according to the view of nurses from a maternity. Revista Brasileira de Enfermagem, (2007), 60(2), (207-212).

[7] Catrin Bjorvell: nursing documentation in clinical practice, department of nursing, karolinska institute, Stockholm, 2002, sweeden, page 10 .

[8] Barthlomew, A.I (2010). A guide to nursing process, Owerri; klimann. 
[9] Global health council, Building a Winning Nursing Work Force for HIV-Care in Ethiopia. Accessed on October 14/2010, www.change.org

[10] Freitas, M. C., Queiroz, T. A., \& Sousa, J. A. V.: The nursing process according to the view of nurses from a maternity. Revista Brasileira de Enfermagem, (2007), 60(2), (207-212).

[11] Shea N., McBride, L., Given C., \& Bauer M.: The effects of ambulatory collaboration practice model on process and outcome of care for bipolar disorder. Journal of the American Psychiatric Nurses Association, (1997), 3(2), 49- 57.

[12] Meamarian R. \&Vanaki Z.: Implementing nursing process with facilities in teaching hospitals .Tarbiat Modares University/Medical Science College / Iran/ Tehran (1997).
[13] Törnkvist, L., Gardulf, A. \& StrenderL. The opinions of nursing documentation held by district nurses and by nurses at primary health care centres. Vård i Norden, (1997), 17(4), 1825 .

[14] Tapp R.: Inhibitors and facilitators to documentation of nursing practice. Western Journal of nursing research, (1990) 12(2): $229-240$

[15] Mulugeta Asratie: assessment on factors affecting implementation of nursing process in Addis Ababa, Ethiopia. A thesis presented for Addis Ababa University (2011). 